\title{
Automatic and effortful processes in memory for spatial location
}

\author{
NORMAN R. ELLIS \\ The University of Alabama, Tuscaloosa, Alabama
}

\begin{abstract}
According to Hasher and Zacks (1979), memory for spatial location is automatically encoded and cannot be improved by intent. In this study, groups of subjects viewed 124 photographs on posters ( 4 on each) with instructions to remember the location of $3,6,12$, or 24 targeted photographs. Memory for 3 photographs was significantly improved by instructions over that of the 24-target group and an incidental group. There was also slight improvement in memory for up to 12 photographs over that of the incidental group. Automatic encoding, as reflected by the performance of the incidental group, was the primary mechanism in remembering location. Even though the strong form of the Hasher and Zacks theory was not supported, the main thrust of their position seemed correct.
\end{abstract}

Hasher and Zacks (1979) hypothesized that memory for frequency of occurrence, temporal order, and spatial location is automatically encoded. Research on frequency of occurrence has yielded mixed results; evidence both for and against the Hasher and Zacks position can be adduced. (See Naveh-Benjamin \& Jonides, 1986, Jonides \& Naveh-Benjamin, 1987, and Greene, 1986, for summaries of the findings on frequency of occurrence.) Studies of temporal order have also yielded mixed results with respect to the Hasher and Zacks theory (e.g., see NavehBenjamin, 1990).

Evidence against the Hasher and Zacks (1979) theory as it relates to memory for spatial location has been reported by Naveh-Benjamin $(1987,1988)$. Using a task designed by Mandler, Seegmiller, and Day (1977), he found a number of variables that affected memory for location that should have affected effortful but not automatic processing. These included strategy manipulations, competing concurrent task load, practice, intention, intellectual differences, and age of subjects. Therefore, NavehBenjamin claimed that the encoding of spatial location was effortful or strategic and not automatic. On the other hand, our research on spatial location (Dulaney \& Ellis, in press; Ellis, Katz, \& Williams, 1987; Ellis \& Rickard, 1989; Ellis, Woodley-Zanthos, \& Dulaney, 1989; Katz \& Ellis, in press) suggests that memory for spatial location is automatically encoded.

In a recent paper (Ellis, in press), I have shown that intention, concurrent processing demands, and practice had no effects on memory for spatial location in a task

This research was supported by Grant HD 125558 to Norman R. Ellis from the National Institute of Child Health and Human Development. I wish to thank Cindy Dulaney, Cindy Johnson, and Scott Smith for assistance in data collection and analyses. Requests for reprints should be sent to Norman R. Ellis, Department of Psychology, University of Alabama, P.O. Box 870348, Tuscaloosa, AL 35487-0348. that did not include subtasks requiring effortful processing. I further argued that the complex task used by NavehBenjamin $(1987,1988)$ included effortful subtasks. Yet even though our studies suggest that the encoding of spatial location is mainly automatic, our findings do not fully meet the strong form of the Hasher and Zacks (1979) position. They claimed that automatic processing is optimal, and that it could not be improved effortfully. Some of my data have suggested otherwise. It would appear that memory for location is usually less than perfect in tasks requiring memory for long series of locations, and that memory for a limited number of locations in such a series can be improved strategically. In my task, groups of subjects looked through a 120 -picture book with instructions to remember the location of 1 picture, 6 pictures, 12 pictures, or all 120 pictures. The to-be-remembered pictures were labeled. Another incidental group looked through the book and rated the "usefulness" of pictures. The proportions correctly relocated were $.950, .847, .760$, .788 , and .783 , respectively. Memory for the 1- and 6target groups was significantly improved over that of the other groups, but it was not strategically improved for more than 6 pictures.

The present study confirms and extends this earlier finding, showing the role of both automatic and effortful processing of memory for spatial location.

\section{METHOD}

\section{Subjects}

Seventy-five introductory psychology students participated for course credit. They were assigned equally and without bias to five groups.

\section{Materials}

Four photographs of common objects were mounted on each of 31 posters. The posters $(41 \times 54 \mathrm{~cm})$ were made from black posterboard. The photographs $(17 \times 22 \mathrm{~cm})$ of objects (e.g., a bed, a wallet, an auto, an umbrella) were arranged in quadrants outlined with white paper tape. The posters were held vertically by a rack on a table in front of the subject. 


\section{Procedure}

All subjects were told that this was a study related to media advertising. They were to look through the 124 pictures and say aloud whether or not they had seen each of the pictured objects on the day of the experiment. These were the only instructions given to an incidental group. Four additional groups were given the incidental instructions, but they were also told to remember the location of targeted photographs. A red stick-on label, $2 \mathrm{~cm}$ in diameter, was located in a conspicuous place on the photograph. There were $3,6,12$, and 24 targeted photographs for the four groups. The subjects were told the number of targeted photographs, and the targeted photographs were randomly selected for each subject. However, these photographs were all drawn from a set of 50 that were to be used in the memory test.

The experimenter exposed a poster each $11 \mathrm{sec}$, and the subject said aloud whether or not he or she had seen the objects pictured that day; the experimenter recorded the responses. About 2 min elapsed between study of the posters and the location memory test. During this interval, the experimenter recorded demographic data on the subject and engaged the subject in casual conversation. For the memory test, the subject was given 50 photographs, one at a time, and the subject indicated their original positions on a blank poster. The same 50 test photographs were used for all subjects, and all targeted photographs were included in the set. The test did not include photographs from the first and last three posters. No more than two photographs from a poster were included in the test set.

\section{RESULTS AND DISCUSSION}

Table 1 presents the means and standard deviations of the proportions of target and nontarget photographs correctly relocated along with the proportions correctly relocated by the incidental group. A mixed analysis of variance (ANOVA) comparing the mean proportions correct of the four groups on target and nontarget photographs revealed a significant difference between groups $[F(3,56)=$ $3.07, p=.03]$ and between target and nontarget photographs $[F(1,56)=55.42, p=.001]$. A one-way ANOVA on the target photograph data yielded a significant difference $[F(3,56)=3.16, p=.03]$. A follow-up with Tukey's $H S D$ test showed that the only significant difference (.05) was between the 3- and 24-target groups. A similar analysis that included the incidental group data yielded a significant finding $[F(4,70)=3.82, p=.007]$. Tukey's $H S D$ test revealed significant differences (.05) between the 3-target group and both the 24-target and incidental groups. A one-way ANOVA of the nontarget photograph data for the four groups did not yield significant differences. An analysis that included the incidental group data yielded a significant difference between the 24-target group and the incidental group.

Table 1

Means and Standard Deviations of Proportions of Correct Relocations for Each Group

\begin{tabular}{ccccc}
\hline \multirow{2}{*}{$\begin{array}{c}\text { No. } \\
\text { Photographs }\end{array}$} & $M$ & & \multicolumn{2}{c}{ Nontargets } \\
\cline { 2 - 3 } \cline { 4 - 5 } & \multicolumn{3}{c}{ Target Group } & \\
3 & 91.20 & 15.10 & 66.53 & 12.73 \\
6 & 80.53 & 16.48 & 65.66 & 13.86 \\
12 & 79.93 & 16.45 & 69.33 & 13.22 \\
24 & 73.67 & 15.26 & 58.40 & 12.61 \\
& & Incidental Group & & \\
& & & 72.40 & 9.42 \\
\hline
\end{tabular}

It is apparent that memory for location is facilitated by instruction, and that this augments the automatic memory component. It is also apparent that the effortful process is based on a limited capacity system. Table 1 suggests that there is substantial facilitation for 3 to 6 photographs and possibly some improvement for as many as 12 . Twentyfour targeted photographs are remembered no better than those viewed under incidental instructions. No doubt, the capacity of effortful encoding would vary depending on task constraints. On the other hand, the automatic encoding system seems to have unlimited capacity. In this task, $72 \%$ of the locations were remembered when the subjects did not expect a memory test. In our past studies, subjects remembered approximately $70 \%-80 \%$ of the locations, regardless of instructions and procedural variation.

Memory for the nontarget photographs was significantly poorer than memory for photographs viewed under incidental instructions [65\% vs. $75 \% ; t(73)=2.35, p<.05]$. But this was not due to a tradeoff of attentional resources. Memory for nontarget photographs on posters with targets and on those without targets was not significantly different. The mean percent correct for photographs on posters with targets was $61.7 \%$ and that for photographs on posters without targets was $66.6 \%[F(3,56)=1.22]$. Of course, this difference is mainly due to the low, and seemingly unsystematic, relocation accuracy of the 24target group. These findings do not support the strong form of the Hasher and Zacks (1979) position, which requires that all their criteria for defining automaticity be met. Automatic processing does not result in perfect memory for location, and it can be improved by intent. I (Ellis, in press) have found that memory for location is improved by instructions that lead to a deeper processing of items. Moreover, the locations of more salient stimuli were remembered better than those of less salient stimuli. It is possible that the intentional effects in the present paper resulted from better encoding of items, which indirectly improved memory for location. In any case, both effortful and automatic processes are involved in the encoding of memory for spatial location. However, the latter is clearly the dominant mode of remembering. Even though the Hasher and Zacks (1979) criteria for defining memory for spatial location as an automatic process were not met, the main thrust of their position seems to be essentially correct. The remembering of locations of objects in the environment is predominantly an automatic process.

\section{REFERENCES}

Dulaney, C. L., \& Ellis, N. R. (in press). Long-term recognition memory for items and attributes by retarded and nonretarded persons. Intelligence.

ELlis, N. R. (in press). Is memory for spatial location automatically encoded? Memory \& Cognition, 18, 584-592.

Ellis, N. R., Katz, E., \& Williams, J. E. (1987). Developmental aspects of memory for spatial location. Journal of Experimental Child Psychology, 44, 401-412.

EluIs, N. R., \& RICKARD, T. C. (1989). The retention of automatically and effortfully encoded stimulus attributes. Bulletin of the Psychonomic Society, 27, 299-302.

Ellis, N. R., Woodley-Zanthos, P., \& Dulaney, C. L. (1989). 
Memory for spatial location in children, adults, and mentally retarded persons. American Journal on Mental Retardation, 93, 521-527.

GREENE, R. L. (1986). Effects of intentionality and strategy on memory for frequency. Journal of Experimental Psychology: Learning, Memory, \& Cognition, 12, 489-495.

HASHER, L., \& ZACKS, R. T. (1979). Automatic and effortful processes in memory. Journal of Experimental Psychology: General, 108, 356-388.

JoNides, J., \& NAVEH-BENJAMIN, M. (1987). Estimating frequency of occurrence. Journal of Experimental Psychology: Learning, Memory, \& Cognition, 13, 230-240.

KATZ, E. R., \& Ellis, N. R. (in press). Memory for spatial location in retarded and nonretarded persons. Journal of Mental Deficiency Research.

Mandler, J. M., Seegmiller, D., \& Day, J. (1977). On the coding of spatial information. Memory \& Cognition, 5, 10-16.
Naveh-Benjamin, M. (1987). Coding of spatial location information: An automatic process? Journal of Experimental Psychology: Learning, Memory, \& Cognition, 13, 595-605.

Naveh-Benjamin, M. (1988). Recognition memory of spatial location information: Another failure to support automaticity. Memory \& Cognition, 16, 437-445.

NAVEH-BENJAMin, M. (1990). The effects of rehearsal on temporal order coding. Bulletin of the Psychonomic Society, 28, 181-184.

NAveh-Benjamin, M., Jonides, J. (1986). On the automaticity of frequency coding: Effects of competing task load, encoding strategy, and intention. Journal of Experimental Psychology: Learning, Memory, \& Cognition, 12, 378-386.

(Manuscript received June 9, 1990.)

\section{European Meeting of the Psychometric Society \\ Trier, Germany \\ July 28-31, 1991}

\section{CALL FOR PAPERS}

The 1991 European Meeting of the Psychometric Society will be held at the University of Trier, Germany, July $28-31,1991$.

Persons wishing to present a paper should send: (1) a title; (2) An abstract of about 150 words for the program book; (3) name(s) and institutional affiliation(s) of the author(s), and, if there is more than one author, an indication of who will present the paper; (4) keywords; (5) an indication of how many minutes of the program time will be needed (20 minutes is suggested, discussion included); and (6) an electronic mail address if available.

The deadline for the receipt of paper and symposium proposals is March 1, 1991.

Submissions should be related to one of the following areas: test theory, data analysis, multidimensional scaling, statistical methods, simultaneous equation models, correspondence analysis, measurement theory, multivariate analysis, mathematical models, factor analysis, psychophysical scaling, and classification. An overhead projector and a $35-\mathrm{mm}$ slide projector will be available.

Submissions and requests for further information should be sent to: Rolf Steyer, University of Trier, Fb I-Psychology, Postfach 3825, D-5500 Trier, Germany (Phone: 0651/201 2056). 